\title{
Interacciones genéticas y epigenéticas relacionadas con fisuras de labio y paladar no sindrómicas
}

\section{Genetic and epigenetic interactions related to non-syndromic cleft lip and palate}

\author{
Tirado Amador LR*, Madera Anaya MV**, González Martínez FD***
}

\section{RESUMEN}

En la actualidad, las fisuras de labio y fisuras de paladar no sindrómicas constituyen una de las alteraciones del crecimiento y desarrollo facial con alta prevalencia que ocasiona preocupación a nivel mundial porque generan efectos a nivel fisiológico al repercutir en la deglución, fonación, así como en la autopercepción y aceptación del individuo en lo relacionado con la socialización, ocasionando que el tratamiento de dicha alteración requiera de la utilización de un equipo interdisciplinario con el fin de lograr mejoría satisfaciendo las necesidades del individuo afectado. Con respecto a la etiología de este defecto del desarrollo, en la literatura se ha atribuido a diversos factores genéticos así como a factores ambientales, convergiendo hacia el modelo de interacción multifactorial en el que los genes emiten respuesta ante los estímulos que provienen del ambiente, lo que repercute en la expresión a nivel fenotípico. Aunque existen reportes de los cambios genéticos que pueden estar asociados con las alteraciones en el desarrollo labial y cierre palatino, existe gran tendencia a considerar la presencia de mutaciones; sin embargo en ocasiones se omite o resta cierta importancia a los efectos que derivan de las alteraciones en la expresión de la información genética como resultado de la exposición a ciertos factores ambientales. Por lo cual, en la presente revisión, los autores pretenden describir algunos factores genéticos y epigenéticos que intervienen en la aparición de las fisuras labiales y palatinas no sindrómicas.

Palabras clave: Represión epigenética, labio leporino, fisura del paladar, ambiente, metilación de ADN.

\section{SUMMARY}

At present the non-syndromic cleft lip and cleft palate is one of the impaired growth and development facial with high prevalence and causes worldwide preoccupation because generates effects at the physiological level because impact on swallowing, phonation, as well as the perception and acceptance of the individual on socialization. Resulting a treatment of this alteration with needs the use of an interdisciplinary team in order to achieve improvement to meet the needs of the individual concerned. About the etiology of this developmental defect, in the literature has been attributed to various genetic and environmental factors, converging towards the model multifactorial interaction in which genes emit response to stimuli from the environment, which affects the phenotypic expression level. Although there are reports of genetic changes that may be associated

* Odontóloga. Investigador grupo GISPOUC. Facultad de Odontología. Universidad de Cartagena. Colombia. ** Odontólogo. Magíster en Epidemiología Clínica. Magíster en Bioquímica. Investigador grupo GISPOUC. Facultad de Odontología. Universidad de Cartagena. Colombia.

*** Odontólogo. Especialista en Investigación Social. Magíster en Salud Pública. PhD (c). Toxicología Ambiental. Profesor asociado. Facultad de Odontología. Director del grupo GISPOUC. Universidad de Cartagena. Colombia. 
with alterations in development during palate closure, there is a great tendency to consider the presence of mutations; however occasionally it omitted or subtract some importance to the effects deriving from changes in the expression of genetic information as a result of exposure to certain environmental factors. Therefore in the present review, the authors attempt to describe some genetic and epigenetic factors involved in the emergence of non-syndromic cleft lip and cleft palate.

Key words: Epigenetic repression, cleft lip, cleft palate, environment, DNA methylation.

Fecha de recepción: 3 de junio de 2015.

Aceptado para publicación: 20 de julio de 2015.

Tirado Amador LR, Madera Anaya MV, González Martínez FD. Interacciones genéticas y epigenéticas relacionadas con fisuras de labio y paladar no sindrómicas. Av. Odontoestomatol 2016; 32 (1): 21-34.

\section{INTRODUCCIÓN}

Las malformaciones cráneo faciales más frecuentes en los seres humanos son el Labio leporino y el Paladar hendido (1). La prevalencia de estas afecciones varía según la procedencia geográfica, para los Asiáticos es de 1/300, para los africanos es de 1/ 2.500 y en países Europeos, como Francia, es de 1/ 700 nacimientos (2). En Colombia, este tipo de malformaciones se presentan con una prevalencia de 1:1.000 nacidos vivos y el IV Estudio Nacional de Salud Bucal (ENSAB IV) reportó una prevalencia de labio leporino de 0,04\% y hendidura de paladar 0,02, en tanto que la prevalencia de labio y paladar hendido asociados es de $0,07 \%$ en el total de personas examinadas (3). Se pueden distinguir varias formas clínicas como la fisura labial, la cual puede ser completa, incompleta o microformas, unilateral o bilateral, y puede implicar una fisura palatina completa o incompleta, unilateral o bilateral, o limitarse a la submucosa (4). La clasificación también se ha establecido como no sindrómica y sindrómica, teniendo en cuenta la aparición de la malformación acompañada o no de otras alteraciones congénitas. La etiología de estas alteraciones aún no se encuentra totalmente dilucidada, considerando la interacción de factores internos y factores externos. Se ha sugerido la interacción de algunos factores ambientales y la exposición a ciertas condiciones locales en el organismo; deficiencias nutricionales durante el embarazo, restricciones uterinas físicas en las madres gestantes y mediciones asimétricas en los padres, el desarrollo de estas anomalías también se atribuye a modelos que explican su aparición a partir de las interacciones entre los factores genéticos y el medio ambiente (5). En lo que respecta al estudio de los genes involucrados con la aparición de las fisuras labiales o palatinas, se han postulado modelos que favorecen las anomalías sindrómicas y no sindrómicas (6); mientras que en relación al medio ambiente, algunos estudios han considerado diversos factores como estado nutricional (7), deficiencias de cinc (8), consumo de folato (9) y uso de sustancias como el alcohol (10) y tabaco (11).

El mecanismo mediante el cual los genes están expuestos a ciertas condiciones del medio y estas pueden contribuir al desarrollo de las fisuras labio palatinas (FLAP), aún no se encuentra completamente aclarado, lo que constituye un tópico de particular interés para investigación, por lo cual, la presente revisión tiene como propósito describir las diferentes interacciones que se han evaluado desde la literatura, involucrando los factores genéticos y epigenéticos como factores de riesgo para la aparición de FLAP.

\section{GENÉTICA EN LA ETIOLOGÍA DE FLAP}

En lo referente a factores genéticos, las FLAP sindrómicas poseen patrones de herencia mendeliana, los genes implicados producen no sólo la anomalía orofacial sino también otras alteraciones. Alrededor de 300 síndromes se han reportado asociados a FLAP (12). Por otro lado las fisuras labio palatinas no sindrómicas (FLAPNS) tienen patrones de herencia 
Tirado Amador LR, Madera Anaya MV, González Martínez FD.

poligénicos y los genes que se han estudiado son genes candidatos, es decir genes que han sido detectados en fisuras sindrómicas y que podrían contribuir con la etiología de las FLAPNS. Algunos de los genes que han sido reportados en la literatura son 1q32 del gen (IRF6), 2p13 (TGFA), 4p16 (MSX1), 6p23-25, 14q24 (TGFB3), 17q21 (RARA), 19q13 (BCL3, TGFB1), MTHFR, TBX22, NAT1, NOS3, entre otros $(6,13-16)$.

Dentro de las vías generales de afección genética se ha reportado la existencia de diversas mutaciones asociadas con la aparición de fisuras labiales y palatinas. Es posible identificar la mutación ocasionada por el T-box factor de transcripción TBX22 (14), con estos cambios ocurre la conservación del dominio de 180-aminoácido, lo que induce a la pérdida de la función y a la alteración de la capacidad de la proteína para su modificación post-traduccional (17). Otras vías de mutación incluyen la deleción y traslocación genética, las cuales implican respectivamente, la pérdida de un segmento de ADN o el desplazamiento de algún fragmento hacia un nuevo sitio en el genoma. Incluso se ha considerado que el cromosoma 6 es candidato para la etiología de las fisuras labiales y palatinas, cuando este se encuentra afectado por mecanismos como la deleción y traslocación (18).

Otras mutaciones descritas son por ejemplo aquellas presentes o próximas a la región crítica del IFR6. En un estudio realizado en 2006 se lograron identificar 11 mutaciones que incluían la mutación Pro76Ser que afecta el dominio de unión del ADN que se encuentra directamente implicado en las interacciones del mismo (19). Otras mutaciones como la Phe252Leu, Arg250X, y Ser330X fueron encontradas en el dominio del factor de regulación de unión a interferón, que es necesario para llevar a cabo la homodimerización y heterodimerización de IRF6; además de mutaciones como Cys114X y Gln118X, las cuales son mutaciones de desplazamiento, se ha encontrado Gly189fs asignada a un zona por debajo del dominio de unión al ADN y que provocó una proteína que carecía de factor de dominio de unión regulador de interferón. Así mismo, se expresaron otras mutaciones como Ala2Gly situada por arriba del dominio de unión a ADN, mutación Ala439fs, Arg412X y Tyr403X (19).

\section{Algunos genes candidatos en FLAPNS}

\section{MSX1 (mshhomeobox 1)}

Es un gen codificador de proteínas. En el 2\% de los pacientes con fisuras orofaciales no sindrómicas se ha reportado algún tipo de mutación (20), las cuales se deben a errores transcripcionales en la secuencia codificadora o también a elementos reguladores con conservación alta del gen MSX1, lo que provoca disminución en el desarrollo de las crestas palatinas (21). Estudios en ratones con fisuras en paladar, han demostrado que la mutación en el MSX1 es el resultado de defectos en la proliferación celular en la región mesenquimal anterior del paladar (22).

\section{TGFß (factor de crecimiento transformante beta)}

Este gen, pertenece a la familia de genes del factor de crecimiento y desarrollo, junto a las activinas y proteínas morfogenéticas óseas (BMPS). La familia TGF $\beta$ comprende TGFß1, TGFß2 y TGß3. Estos genes permiten que se desarrollen una serie de procesos biológicos como la proliferación celular, diferenciación celular, transformación del epitelio mesenquimal, migración y apoptosis; por su parte el TGFß1 y TGFß2 favorecen la aproximación de los procesos verticales y horizontales para la fusión del paladar, mientras que el TGFß3 contribuye a la degradación de membranas y regula la respuesta de las metaloproteinasas, las cuales intervienen en la remodelación de la matriz extracelular, proceso que es indispensable para la fusión del paladar. La función del TGFß3 es principalmente contribuir con la elaboración de la costura epitelial. Este se expresa en los componentes epiteliales de la cresta vertical y luego en las crestas horizontales y borde medio palatino (6). Este gen ha sido estudiado, considerando que la existencia de un polimorfismo de nucleótido único puede favorecer una mutación capaz de generar efectos en la palatogénesis. Un estudio realizado por Kim (23) en Corea, reveló que existe un riesgo para fisuras orofaciales de aproximadamente 16 veces cuando se presenta un polimorfismo de un solo nucleótido. Algunas asociaciones alélicas y haploides implican una posible intervención de TGFß3 en el desarrollo de fisuras labiales y palatinas, como ha 
sido reportado por diversos estudios en animales y humanos; sin embargo el mecanismo no se encuentra en su totalidad decodificado (24). Se ha sugerido que la inhibición de la actividad del TGF- $\beta 3$ normal, a causa de oligodesoxinucleótidos-antisentido o de un anticuerpo neutralizante, pueden dar lugar a la falta de la fusión palatina (25).

\section{IRF6}

Este es considerado un gen de codificación de proteínas, que constituye un elemento clave en el desarrollo oral y maxilofacial, por lo que los cambios en el mismo se convierten en un factor de riesgo significativo para las fisuras labiales y palatinas y es actualmente un descubrimiento prometedor, ya que es constituye una evidencia de que se pueden mapear las variantes genéticas que intervienen para la aparición de estas alteraciones (6). Hasta la fecha, por lo menos 200 diferentes mutaciones en el gen IRF6 se han descrito, la mayoría asociadas a mutaciones por supresión de alguna proteína (26). La alteración se ha relacionado con una forma sindrómica de fisuras orofaciales, conocida como el síndrome de Van der Woude, en donde se ha identificado una variante polimórfica común de un nucleótido único, en esta se presenta la sustitución de la isoleucina por una valina en posición 274 (V274I) del aminoácido en el dominio de unión a proteínas del IRF6 (21). Otros estudios han revelado polimorfismos de nucleótidos únicos presentes en familias italianas tales como rs2013162 y rs2235375 (27).

\section{TGFA (Factor de crecimiento transformante alfa)}

TGFA es una proteína secretora que ofrece un ligando para el receptor del factor de crecimiento epidérmico. Interviene en procesos como la proliferación celular, diferenciación, migración y apoptosis. Esta se ha localizado en el epitelio durante fases previas y posteriores a la fusión del paladar (28). En los estudios de la relación entre el TGFA y las fisuras orofaciales se ha determinado que no es un factor determinante, pero que se comporta como un factor modificador (28). Hay reportes que evidencian una posible variación en la secuencia de ADN de TGFA (alelo Taql C2), que combinada con la exposición de la madre al tabaquismo durante el primer trimestre de gestación, puede inducir al desarrollo de FLAPNS con un riesgo incrementado entre 6 y 8 veces para fisuras palatinas (29) y el doble de riego para fisuras labiales (30).

\section{MTHFR}

Es un gen candidato para fisuras labio alveolo palatinas, que se encuentra localizado en el sitio cromosomal 1p36.3. La importancia de este gen radica en que codifica la 5, 10 metilen-tetrahidrofolato-reductasa, una enzima con 650 aminoácidos, con la función de generar la forma activa del folato, 5 metilentetrahidrofolato que es necesaria para las células. La importancia del folato consiste en intervenir en el metabolismo de ácidos nucleicos y aminoácidos, indispensables para la síntesis de nucleótidos y, en consecuencia, para la división celular, que es fundamental en el desarrollo. Una alteración en la actividad de la MTHFR puede provocar una disminución de los niveles de folato y por consiguiente alterar la síntesis de ácidos nucleicos. Algunos polimorfismos asociados a este gen son el C-a-T en el nucleótido 677 , en donde se presenta una sustitución en la posición 677, que convierte una Alanina a una Valina en el residuo 222 aminoácido (A222V; rs1801133) (13). Este polimorfismo se asocia con disminución de las concentraciones de folato en suero, plasma, y eritrocitos; así como a ligeros incrementos de los niveles de homocisteína plasmática total. Otro polimorfismo que se ha identificado es A1298C, en donde hay una sustitución de ácido glutámico por Alanina en el codón 429 (G429A), que afecta la actividad de MTHFR, pero sin provocar cambios bioquímicos (31).

\section{6. $T B X 22$}

Es un gen que pertenece a la familia de genes que poseen factores de transcripción conservados. Este gen interviene en procesos del desarrollo temprano, a nivel del mesodermo precordal, el cual permite originar tejidos especializados y no especializados como son tejidos óseos y cartilaginosos. Las mutaciones reportadas en el T-box factor de transcripción TBX22 se caracterizan por la conservación de domi- 
nios de ADN (14). Una de las mutaciones reportadas es aquella que incluye la conservación del dominio de 180-aminoácido que provoca la pérdida de la función y es posible que afecte la capacidad de la proteína para su modificación post-traduccional $(17,27)$. Otras vías de mutación pueden ser deleciones en las que se puede perder un segmento de ADN o se pueden presentar traslocación genética, que implica que se desplace un fragmento de ADN hacia un sitio diferente al sitio de procedencia dentro del genoma.

\section{17q12-q21 (RARA, Clf1)}

La importancia del ácido retinoico en el desarrollo y la mediación por parte de miembros de la familia de receptores de ácido retinoico ha sido reportada por estudios en animales y seres humanos con resultados un tanto contradictorios, ya que algunos hallazgos han sido positivos y otros no en lo que respecta al gen RARA para el desarrollo facial, debido a que el locus del receptor alfa del ácido retinoico ha sido relacionado con la ingesta de vitamina A con efectos a nivel de la respuesta celular (32).

\section{FACTORES EPIGENÉTICOS INVOLUCRADOS EN EL DESARROLLO DE FLAP}

Los humanos poseen un código genético capaz de variar debido a causas metabólicas. En algunas ocasiones se pueden heredar lecturas inadecuadas de los genes, conocidas como polimorfismos de nucleótido único (33); sin embargo existen otras variaciones que provienen de algunos grupos químicos pequeños capaces de unirse a las proteínas cromosómicas y a los genes con el fin de regular la expresión. Durante la fase de división de las células progenitoras y cuando las células hijas se diferencian, estos grupos químicos se adhieren a los genes y durante toda la vida de la célula se copiaran, generando un mecanismo epigenético (34) (Figura 1).

La epigenética se ha definido como el estudio de los cambios mitóticos y meióticos en las funciones de los genes sin alterar la secuencia del ADN (35), lo que quiere decir que incluye todos los cambios heredables en la expresión del gen o en su información sin implicar que la secuencia de ADN se modifique. La regulación epigenética incluye tres mecanismos que son la metilación del ADN, acetilación de histo-

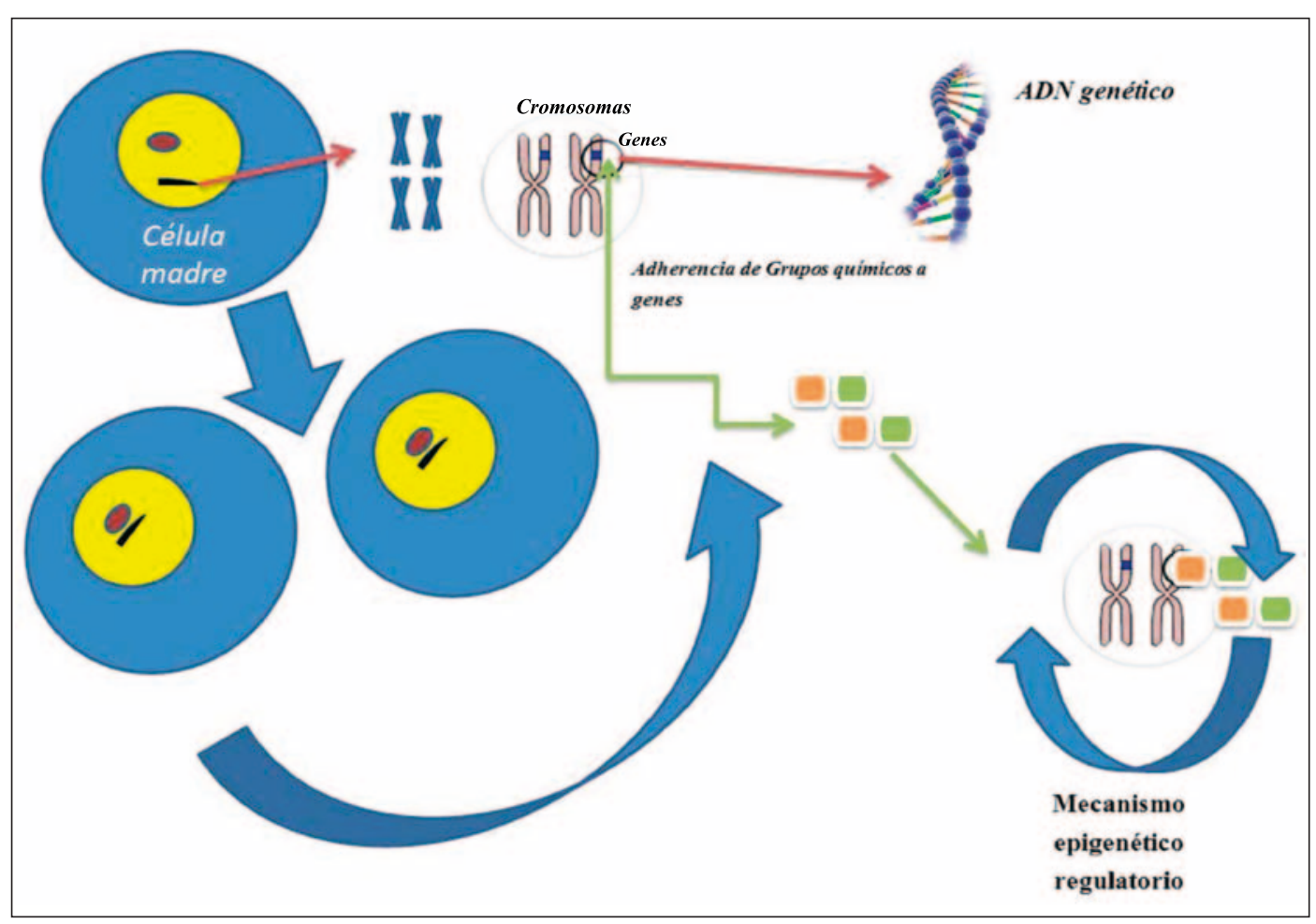

Fig. 1. La regulación epigenética por adherencia de grupos químicos a genes durante la división y diferenciación celular sin alterar la secuencia del ADN. Se observa que la célula madre experimenta durante la división y diferenciación celular la adhesión de algunos grupos químicos a sus genes, esta unión no altera la secuencia del ADN que será heredado por las células hijas pero si afectará la expresión de la información. 
nas y modificaciones en la cromatina. De estos mecanismos se ha sugerido que el más importante es la metilación del ADN (36) (Figura 2).

Para que los mecanismos epigenéticos puedan desarrollarse es necesario que se vinculen a los genes algunos factores del medio ambiente, capaces de influir en la información que se expresará a futuro. En este modelo la etiología de las fisuras labio palatinas se describe mediante los pequeños cambios experimentados en la información del ADN que se origina a partir de factores ambientales. Por su parte, Grosen y cols. muestran que las contribuciones ambientales para los tipos de fisuras es de 9\% para las fisuras labiales/palatinas y de $10 \%$ para las fisuras palatinas (37).
En lo referente al medio ambiente, se han destacado exposiciones a ciertas sustancias o a condiciones sistémicas en el organismo de las madres gestantes. Dentro de estos factores se ha reportado la ingesta de alcohol y hábito de fumar (38), factores nutricionales asociados a vitamina A (37), consumo de folato y suplementos de ácido fólico $(9,39)$.

\section{Metilación del ADN en la aparición de FLAPNS}

La metilación del ADN desempeña en el genoma humano una clave epigenética crucial para regular cambios y mantenimiento de la memoria celular, lo que contribuye con procesos necesarios para el desarrollo fetal como determinar el destino celular, la

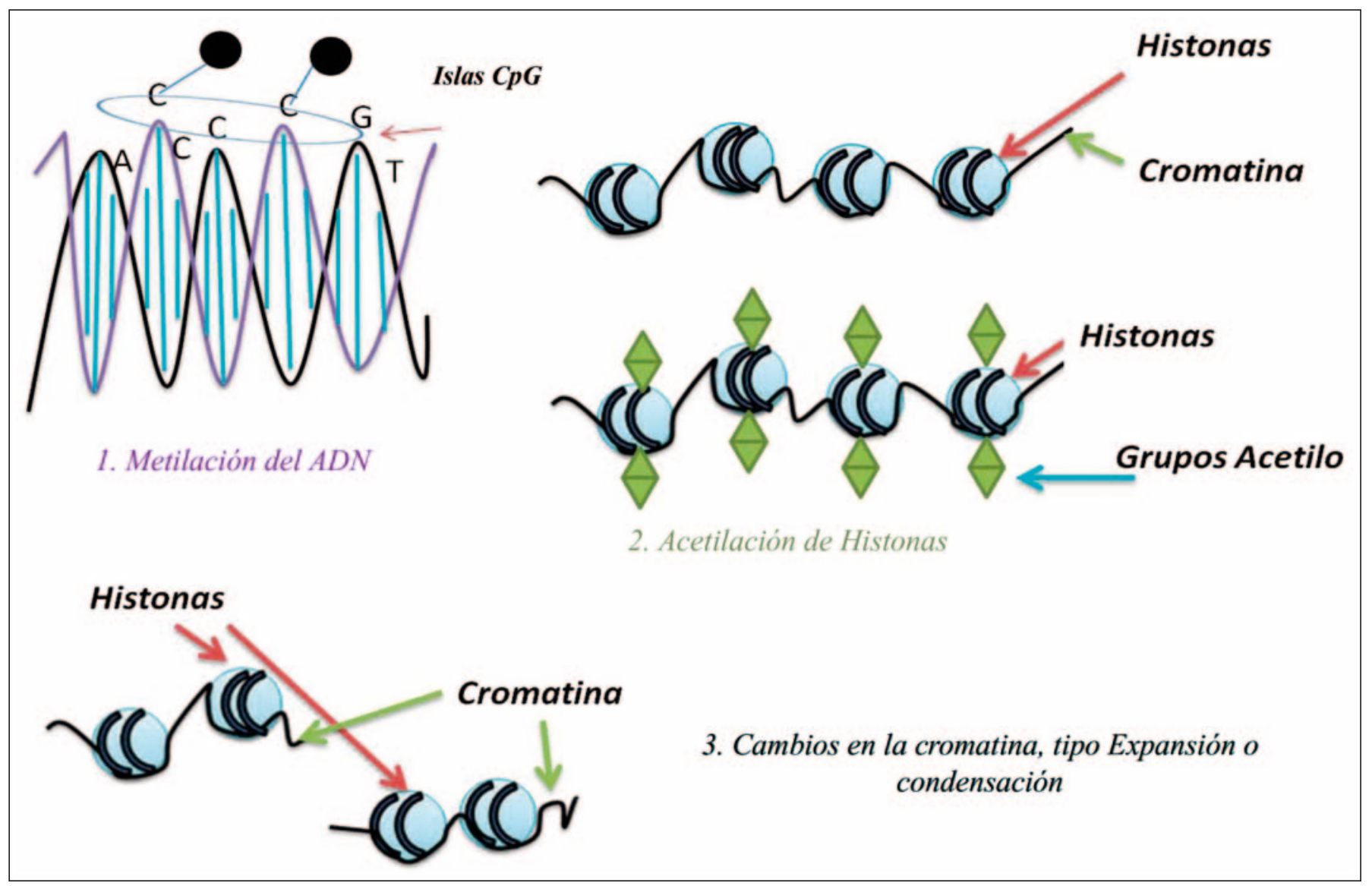

Fig. 2. Diferentes mecanismos epigenéticos. 1) Se muestra la adhesión de grupos metilos (representados por esferas negras) a bases citosinas (C) del ADN situadas previa y contiguamente a una guanina (G), este mecanismo epigenético es la metilación. 2) Se presenta la adición de un grupo acetil a un residuo de lisina en el $\mathrm{N}$ - terminal de la histona, mecanismo epigenético con el que se logra reducir las cargas positivas para inducir una reducción de la afinidad entre las histonas y el ADN. 3) La estructura de la cromatina puede influir en la activación de genes, al estar en expansión permite el acceso de la maquinaria celular a los genes para la síntesis de proteínas, en caso de cromatina en condensación se bloquea el acceso a los genes. 
formación de patrones y la diferenciación terminal (40). El genoma humano presenta un grado de metilación extenso (41). En los nucleótidos de citosina del ADN se agregan grupos metilo para captar una serie de proteínas que se encargan de impedir que los factores de transcripción se unan al ADN para activar la expresión de los genes; es por este mecanismo que la metilación del ADN modifica la expresión de los genes (42). Específicamente los cuerpos de genes o unidades de transcripción se encuentran mayormente metiladas que las regiones intergénicas circundantes (43). Algunos autores han documentado consecuencias funcionales de la metilación en lo que respecta a la configuración de la cromatina y la regulación transcripcional; también se ha sugerido que esta contribuye con la supresión de la proliferación de elementos transponibles, pero el efecto de la metilación sobre el cuerpo de genes aún no es del todo clara (44). Es importante resaltar que la alteración en los procesos de metilación se relaciona con defectos del tubo neural (45) y con aparición de fisuras labiopalatinas, ya que la transcripción del ADN no sólo depende de la presencia o ausencia de factores de transcripción, sino que también, requiere de la regulación para que los factores puedan acceder al ADN.

Existen dos mecanismos sugeridos para intentar explicar el efecto inhibidor de la metilación en la transcripción del ADN. Por su parte la 5-metilcitosina (5m C) que se genera de la adición enzimática de un grupo metilo al carbono 5 de la citosina (46), constituyen cerca del $1 \%$ del total de bases presentes en el ADN (35). Estos complejos se encargan de impedir la unión de ciertos factores de transcripción que poseen secuencias $\mathrm{CpG}$ en sitios de reconocimiento, logrando la modificación en la unión de factores de transcripción tales como CREB, E2F, NFkB (47). Otro mecanismo incluye en su desarrollo la participación de complejos proteicos, los cuales se van a unir de forma selectiva a CpG metilados, impidiendo de forma indirecta que los factores de transcripción se unan, como consecuencia de esto, se limita el acceso a los elementos regulatorios. Estos complejos proteicos y proteínas capaces de intervenir en el mecanismo de represión transcripcional, comparten la característica de contener dominios conservados de unión al ADN metilado, algunas de estas son MeCP2, MBD1, MBD2, MBD3. Tanto la síntesis como la transcripción del ADN son esenciales para la divi- sión celular rápida que ocurre durante el desarrollo fetal temprano. Al existir alteraciones durante la transcripción del ADN existe la posibilidad de que la información que se transferirá hacia el ARNm, con el fin de continuar el proceso hacia la obtención de la síntesis proteica, no sea la información adecuada, lo cual puede alterar la expresión y función de algunos genes que intervienen en la palatogénesis, generando una formación y cierre de los procesos palatinos incompletos o alterados, producto de la señalización incorrecta (48) (Figura 3).

\section{Relación epigenética entre alcohol y FLAPNS}

El patrón de Metilación del ADN es establecido por primera vez durante la gastrulación (49), pero en el transcurso del desarrollo fetal y de la vida puede experimentar modificaciones. De esta manera la exposición al alcohol puede generar diversas secuelas, como la perturbación del metabolismo del carbono con la siguiente alteración de los sustratos necesarios para la metilación del ADN. La exposición a etanol, genera varios efectos en los grupos donantes de metilo (50), esta propiedad teóricamente puede generar cambios conocidos como epigenéticos (51). En algunos estudios desarrollados en animales, se ha mostrado la existencia de un puente que permite la interacción entre genes y ambiente, lo que puede conducir a un nuevo mecanismo; trastorno del espectro alcohólico fetal (52). El mecanismo consiste en la inhibición del folato mediado por la síntesis de la metionina, que genera la interrupción de los procesos de metilación dirigidos por la forma activada de la metionina (S-adenosil metionina). El alcohol parece interferir con la ruta metabólica del folato-metilo para donantes de metilo, mediante la inhibición de la sintasa de metionina y adenosil metionina transferasa, provocando un aumento de los requerimientos de colina para utilizarla como donante de carbonos (51).

Otros estudios realizados en animales, evalúan el efecto de la exposición al alcohol durante el desarrollo embrionario temprano en los patrones de metilación del ADN en todo el genoma, utilizando de manera controlada un sistema de cultivo de todo el embrión y dosis de alcohol. Es importante destacar que los hallazgos señalan que muchos de los genes muestran cambios asociados con el efecto causado 


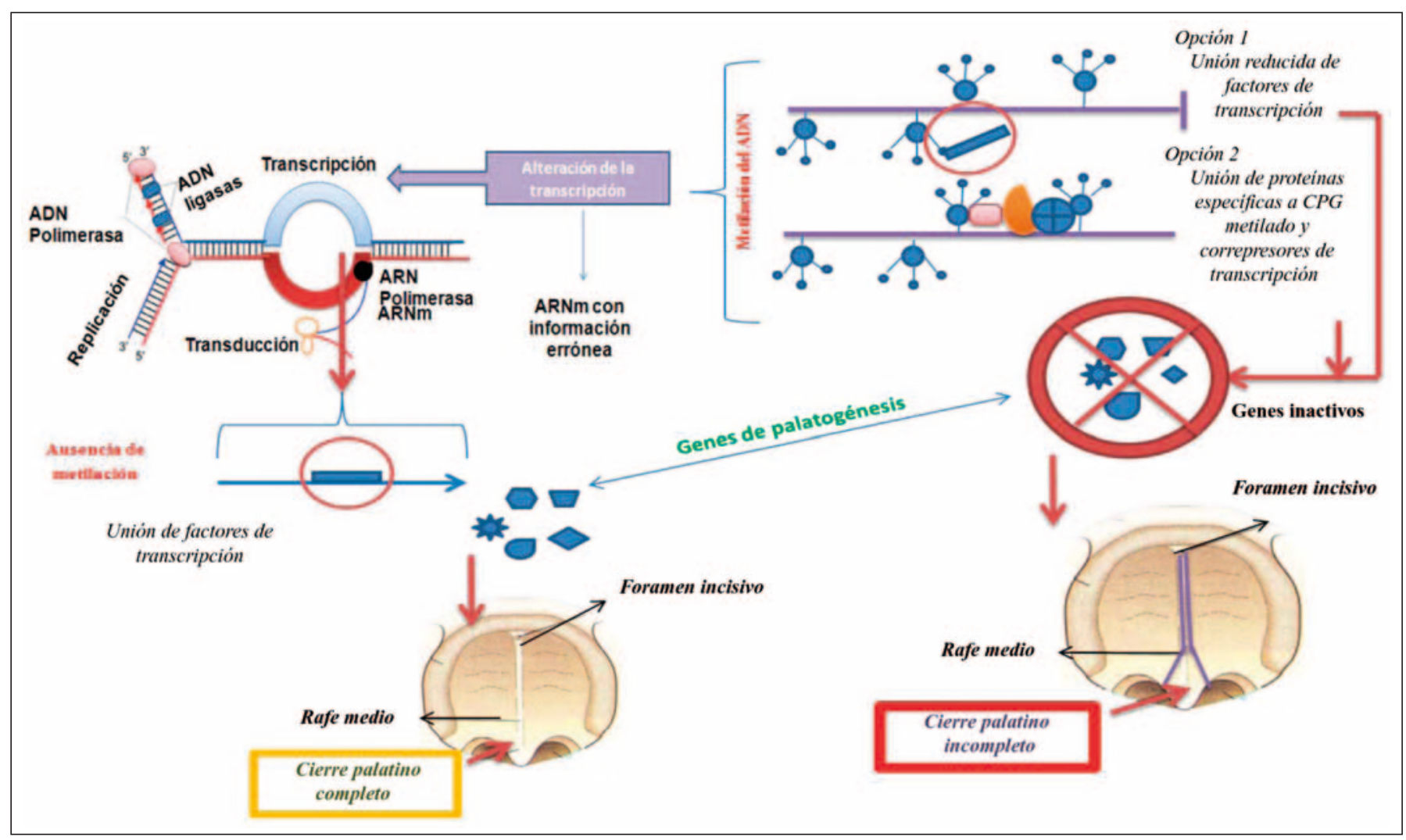

Fig. 3. Efecto de la metilación del ADN en la aparición de FLPNS. Durante la transcripción del ADN es necesaria la participación de factores de transcripción y de mecanismos regulatorios para que otros factores puedan acceder al ADN. En ausencia de metilación se unen

adecuadamente los factores de transcripción y se logran obtener genes activos que participan en la palatogénesis, en tanto que durante la metilación puede generarse unión reducida de factores de transcripción o unión de correpresores, esto genera RNAm con información errónea con la aparición de genes inactivos que no podrán intervenir en la palatogénesis.

por el alcohol en la metilación; así como cambios en la expresión del ARNm, concluyéndose que el consumo de alcohol tiene el potencial de modificar epigenéticamente genes críticos que intervienen en el neurodesarrollo y por consiguiente en el desarrollo craneofacial (52). Estos efectos a nivel materno se traducen en hipometilación, y a nivel paternal, el alcohol altera la metilación de los genes impresos en el gameto masculino y en el esperma paterno se genera la reducción de los niveles de RNAm metiltransferasa de citosina $(53,54)$ (Figura 4).

\section{Relación epigenética entre cigarrillo y FLAPNS}

Aunque poco se sabe aún acerca de la susceptibilidad genética a las toxinas en el humo del cigarrillo, en múltiples estudios se ha presentado una asociación positiva entre hábito de fumar cigarrillos por la madre durante la etapa gestante y el desarrollo de fisuras orofaciales (55). Más recientemente en un estudio de caso-control desarrollado en China en 2011, se evaluó el riesgo de incremento en FLAP en niños cuyas madres fumaron durante la gestación y se encontró un riesgo de aproximadamente 3 veces y media de mayor probabilidad de que los niños nazcan con fisuras si provienen de madres fumadoras (15); sin embargo el mecanismo de acción del tabaco a nivel epigenético sobre el ADN aún no se encuentra totalmente explicado. Los hallazgos sugieren una explicación hacia el polimorfismo genético asociado a variantes polimórficas de la $\mathrm{N}$ - acetil transferasa fetal (NAT1) (15), una enzima que interviene en la fase II de desintoxicación de los constituyentes del humo del tabaco (56). Las NAT transfieren un grupo acetilo a una amina, hidracina, hidroxilamina y resto de un compuesto aromático. El tipo NAT1 contribuye en la mayor parte de 


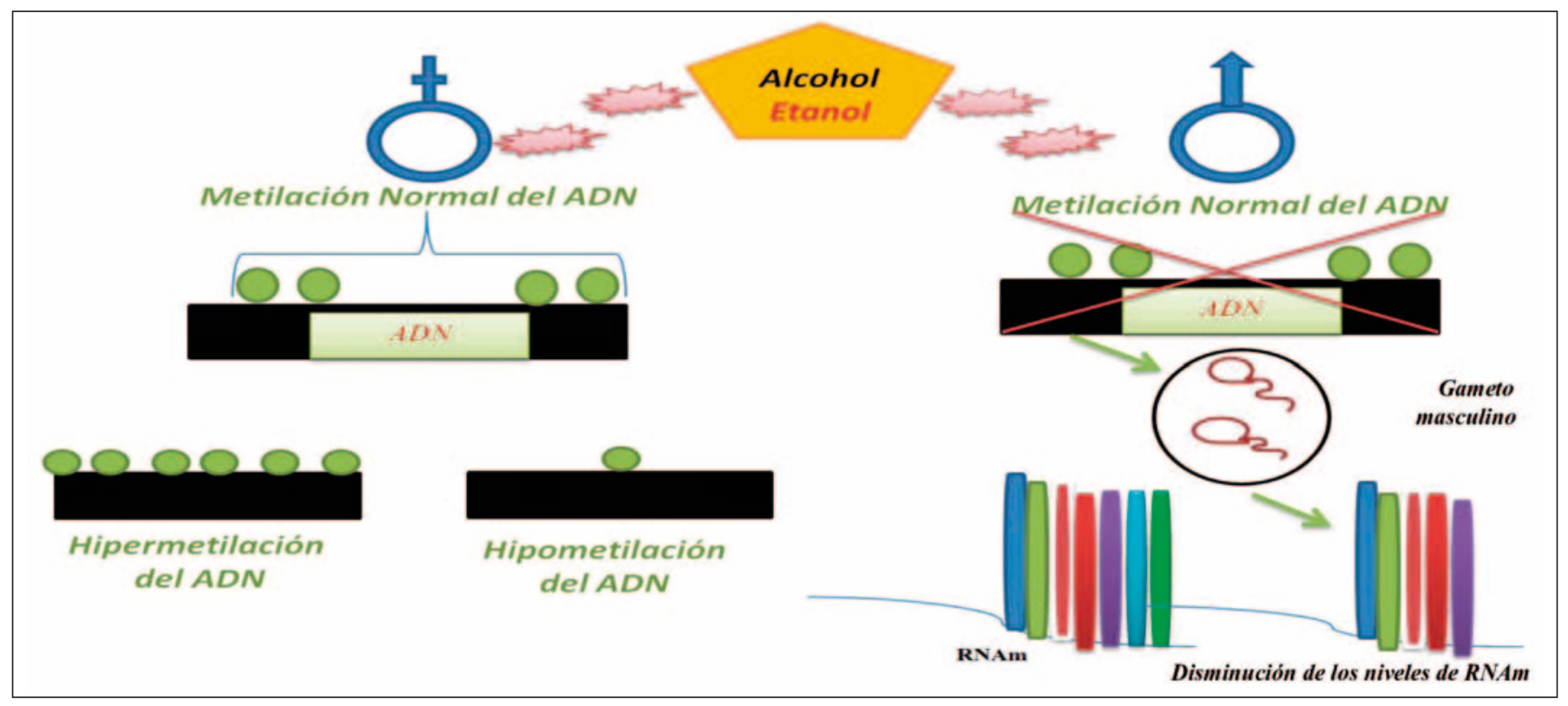

Fig. 4. Efecto epigenético en FLPNS generado por el alcohol según el género. En la mujer, la ingesta de alcohol puede inducir hipometilación del ADN; en el hombre, la ingesta de alcohol altera la metilación de los genes presentes en el espermatozoide y se reduce el nivel de la enzima que interviene en la síntesis de RNAm con la siguiente reducción en los niveles del mismo.

la $\mathrm{N}$ - acetilación durante el primer trimestre del desarrollo embrionario. Por lo tanto, la capacidad fetal para la biotransformación de aminas aromáticas puede contribuir al desarrollo potencial de toxicidad (56). Así mismo, en otro estudio se evaluó la óxido nítrico sintasa endotelial (NOS3), la cual se encarga de regular la producción de óxido nítrico y se expresa en células endoteliales humanas y de embriones de ratón. El polimorfismo de un solo nucleótido (SNP) se asoció con las concentraciones de homocisteína. Algunos investigadores han propuesto que el óxido nítrico modulado por los niveles de homocisteína genera un efecto en el catabolismo de folato. Otros estudios han demostrado que la actividad de la NOS3 es alterada tras fumar cigarrillos. Dado que el riesgo de fisura se ha asociado con el tabaquismo materno y la falta de suplementos de ácido fólico (que da lugar a concentraciones plasmáticas de homocisteína superiores), se concluyó que la variación genética en NOS3 puede interactuar con estas dos exposiciones (16).

\section{Mecanismo de acción epigenética del folato}

La ingesta de ácido fólico en mujeres en estado periconcepcional y su relación con la aparición de las fisuras labio alveolo palatinas se ha documentado en varios estudios (57). Para explicar el mecanismo epigenético se consideró que el folato por ser un donador de carbonos, interviene en la biosíntesis de las purinas y pirimidinas y en la remetilación de la homocisteína, que produce grupos metilo para la metilación de ADN, proteínas, y lípidos. Por esto el folato es necesario para la regulación en la expresión de genes que se requieren para la multiplicación celular y diferenciación durante la embriogénesis (58) (Figura 5).

Los polimorfismos en los genes que codifican las enzimas que participan en el metabolismo de la homocisteína, tales como metilen-tetrahidrofolato-reductasa (MTHFR), metionina sintasa (MTR) y la metionina sintasa-reductasa (MTRR), se han relacionado con defectos del tubo neural, espina bífida y mecanismos predisponentes para fisuras labiales y palatinas (59). La enzima metilen-tetrahidrofolatoreductasa (MTHFR) ha sido destacada en varios estudios por la relación con las fisuras orofaciales, con el fin de entender el rol específico que desempeña en su etiología (60).

Una de las explicaciones desde la perspectiva epigenética consiste en la existencia de dos polimorfis- 


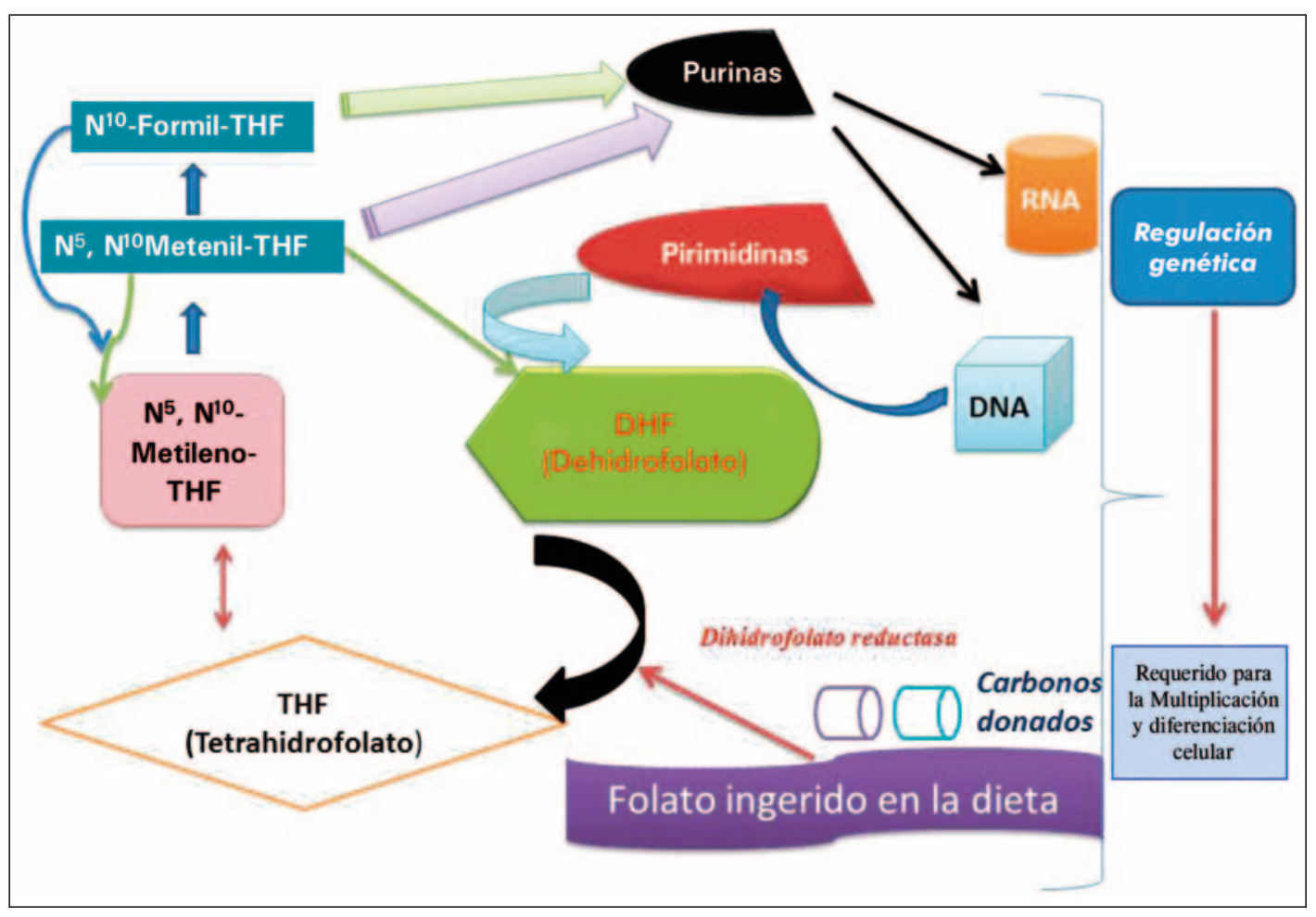

Fig. 5. Importancia del folato como regulador de la expresión genética. El folato participa en la regulación genética indispensable para la multiplicación celular y diferenciación durante la embriogénesis, pues es un donador de carbonos los cuales contribuyen a la síntesis de las bases nitrogenadas (purinas y pirimidinas) que participan en la síntesis de Ácidos nucleicos (ADN y ARN); además interviene en la remetilación de la homocisteína, que produce grupos metilo para la metilación de ADN, proteínas y lípidos. mos a nivel del gen MTHFR, uno C677T y AL298 C, el primero puede provocar una sustitución de transición en la que hay un cambio de alanina por valina en la posición 222, esto ocasiona una disminución de la actividad de la enzima en un 50 \%. Esta enzima es crucial, debido a que se encarga de transformar el 5, 10 tetrahidrofolato en 5 tetrahidrofolato que es la forma libre en que se encuentra el folato y es donador de carbonos para la remetilación de homocisteína a metionina. Cuando la enzima no puede ejercer su función los niveles de folato disminuyen, lo cual interviene para la Síntesis de ADN / ciclos de metilación, ya que el folato participa en la síntesis de nucleótidos. Al mismo tiempo, el posterior aumento de homocisteína celular revierte la acción de S-adenosil-homocisteína-hidrolasa, produciendo niveles elevados de esta enzima, la cual es un potente inhibidor de la ADN metiltransferasa. Por lo tanto, el crecimiento embrionario y el desarrollo normal dependen de la cantidad adecuada de folato celular y de moderados niveles de homocisteína (61). Por lo que en algunos estudios se ha concluido que el riesgo de tener un niño con fisuras orofaciales aumenta cuando se utilizan inhibidores de la tetrahidrofolato-reductasa, debido a que se produce una hiperhomo- cisteinemia durante el segundo y tercer mes después del último periodo menstrual, pero no antes o después de este período (62). El efecto del uso del folato de manera independiente a otras vitaminas en el riesgo de desarrollar labio leporino o paladar hendido en la descendencia, se ha documentado con valores hasta de un $13 \%$ mayor de ácido fólico en las madres que no tienen hijos con fisuras orofaciales en comparación a las madres que sí poseen niños con estas fisuras, lo que genera una reducción en la incidencia de estas alteraciones en aproximadamente un $50 \%$ (63).

\section{CONCLUSIONES}

Existen múltiples genes involucrados en la aparición de fisuras labio palatinas, la interacción de los mismos con diversos factores ambientales puede inducir cambios epigenéticos, que no corresponden a cambios en la secuencia del ADN como si sucedería si existiera una mutación, pero si obedece a un cambio en la expresión de la información. Por esto se han realizado diversos modelos, para identificar los distintos genes que se asocian con estas anomalías 
y las distintas exposiciones que inducen mecanismos epigenéticos.

Con respecto al componente genético de FLAPNS se ha encontrado poca herencia mendeliana por lo que clásicamente se considera oligo o poligénica multifactorial. Dentro de los genes más importantes y utilizados en las replicaciones de distintos estudios se puede mencionar el TGFA (factor de crecimiento transformante alfa), otros miembros de la superfamilia de factores transformantes los cuales intervienen durante el desarrollo del paladar por intervenir en la degradación de membranas; el IRF6 (Factor regulador de interferones 6 ) identificado mediante genes candidatos por estar asociado con una de las formas sindrómica de FLAP presente en el síndrome de Van der Woude. Adicionalmente mutaciones en los genes involucrados en las vías de señalización de Wnt y BMP, tales como el gen MSX1 (MSH homeobox 1); así como el MTHFR que codifica para la enzima metilen-tetrahidrofolato reductasa, relevante para la obtención de la forma activa del folato y TBX22 (Factor de transcripción caja T 22), entre otros.

Existen otros factores que intervienen en los procesos del desarrollo y dentro de los que se pueden considerar los grupos metilo que provienen de la nutrición y el metabolismo los cuales son indispensables para la metilación del ADN, que es un proceso que influye en la conformación estructural de la cromatina y la expresión génica. Los mecanismos reguladores de la expresión de la información contenida en el ADN sólo están empezando a descubrir y la comprensión desde una perspectiva genética y epigenética cambia constantemente, otorgando importancia a un factor específico en tanto que en otras lo atribuye a otros factores. Sin duda, la explicación epigenética en la etiología de las fisuras labiales y palatinas responde a un modelo multifactorial, en la que el mecanismo más destacado es la metilación del ADN.

\section{BIBLIOGRAFÍA}

1. Grollemund B, Guedeney A, Vázquez MP, Picard A, Soupre V, Pellerin P, et al. Relational development in children with cleft lip and palate: influence of the waiting period prior to the first surgical intervention and parental psychological perceptions of the abnormality. BMC Pediatrics 2012;12:65. DOI: 10.1186/1471-2431-12-65.

2. Bhaskar LV, Murthy J, Venkatesh Babu G. Polymorphisms in genes involved in folate metabolism and orofacial clefts. Arch Oral Biol 2011;56(8):72337. DOI: 10.1016/j.archoralbio.2011.01.007. Epub 2011 Feb 18.

3. Estudio nacional de Salud Bucal ENSAB IV. Ministerio de Salud y Protección social de Colombia. Disponible en: http://www.minsalud.gov.co/sites/rid/Lists/ BibliotecaDigital/RIDE/VS/PP/ENSAB-IV-SituacionBucal-Actual.pdf.

4. Goodacre T, Swan M. Cleft lip and palate: current management 2008;18(6):283-92. DOI:10.1016/j.paed. 2008.03.008.

5. Hozyasz K. The search for risk factors that contribute to the etiology of non syndromic cleft lip with or without cleft palate in the polish population. Pediatr pol 2010;85(6):609-23. DOI:10.1016/S0031-3939 (10)70562-X.

6. Stanier P, Moore GE. Genetics of cleft lip and palate: syndromic genes contribute to the incidence of nonsyndromic clefts. Hum Mol Genet 2004;13:R73-81. Epub 2004 Jan 13.

7. Stott-Miller M, Heike CL, Kratz M, Starr JR. Increased risk of orofacial clefts associated with maternal obesity: case-control study and Monte Carlo-based bias analysis. Paediatr Perinat Epidemiol 2010;24(5): 502-12. DOI: 10.1111/j.1365-3016.2010.01142.x.

8. Munger RG, Tamura T, Johnston KE, Feldkamp ML, Pfister R, Carey JC. Plasma zinc concentrations of mothers and the risk of oral clefts in their children in Utah. Birth Defects Res A Clin Mol Teratol 2009;85(2): 151-5. DOI: 10.1002/bdra.20516.

9. Wilcox AJ, Lie RT, Solvoll K, Taylor J, Mcconnaughey DR, Abyholm F, et al. Folic acid supplements and risk of facial clefts: national population based case-control study. Br Med J 2007;334(7591):464-70. Epub 2007 Jan 26.

10. Grewal J, Carmichael SL, Ma C, Lammer EJ, Shaw GM. Maternal periconceptional smoking and alcohol consumption and risk for select congenital anomalies. Birth Defects Res A Clin Mol Teratol 2008;82(7):51926. DOI: 10.1002/bdra.20461.

11. Li Z, Liu J, Ye R, Zhang L, Zheng X, Ren A. Maternal passive smoking and risk of cleft lip with or without cleft palate. Epidemiology 2010;21(2):240-2. DOI: 10.1097/EDE.0b013e3181c9f941. 
12. Escobar L, Prada J, Téllez C, Castellanos J. Bases genéticas de la formación de fisuras labiales y/o palatinas en humanos. CES odontol. [serial on the Internet]. 2013 Jan [cited 2015 July 17];26(1):57-67. Disponible en: http://www.scielo.org.co/scielo.php?script= sci_arttextEpid=S0120-971X2013000100006Elng=en.

13. Aşlar D, Özdiler E, Altuğ AT, Taştan H. Determination of Methylenetetrahydrofolate Reductase (MTHFR) gene polymorphism in Turkish patients with nonsyndromic cleft lip and palate. Int $\mathrm{J}$ Pediatr Otorhinolaryngol 2013;77(7):1143-6. DOI: 10.1016/j.ijporl.2013.04.022. Epub 2013 May 29.

14. Braybrook C, Doudney K, Marçano AC, Arnason A, Bjornsson A, Patton MA, et al. The T-box transcription factor gene TBX22 is mutated in X-linked cleft palate and ankyloglossia. Nat Genet 2001;29(2):179-83.

15. Zhang B, Jiao X, Mao L, Xue J. Maternal cigarette smoking and the associated risk of having a child with orofacial clefts in China: a case-control study. J Craniomaxillofac Surg 2011;39(5):313-8. DOI: 10.1016/ j.jcms.2010.07.005. Epub 2010 Sep 15.

16. Shaw GM, Iovannisci DM, Yang W, Finnell RH, Carmichael SL, Cheng S, et al. Endothelial nitric oxide synthase (NOS3) genetic variants, maternal smoking, vitamin use, and risk of human orofacial clefts. Am J Epidemiol 2005; 162(12):1207-14. Epub 2005 Nov 3.

17. Andreou AM, Pauws E, Jones MC, Singh MK, Bussen $M$, Doudney K, et al. TBX22 missense mutations found in X-linked cleft palate (CPX) patients affect DNA binding, sumoylation and transcriptional repression. Am J Hum Genet 2007;81(4):700-712. Epub 2007 Aug 16.

18. Letra A, Menezes R, Fonseca RF, Govil M, McHenry T, Murphy MJ, et al. Novel cleft susceptibility genes in chromosome 6q. J Dent Res 2010;89(9):927-32. DOI: 10.1177/0022034510370004. Epub 2010 May 28.

19. Du X, Tang W, Tian W, Li S, Li X, Liu L, et al. Novel IRF6 mutations in Chinese patients with Van der Woude syndrome. J Dent Res 2006; 85(10):937-40.

20. Suzuki Y, Jezewski PA, Machida J, Watanabe Y, Shi M, Cooper ME, et al. In a Vietnamese population, MSX1 variants contribute to cleft lip and palate. Genet Med 2004;6(3):117-25.

21. Zucchero TM, Cooper ME, Maher BS, Daack-Hirsch $\mathrm{S}$, Nepomuceno B, Ribeiro L, et al. Interferon regulatory factor 6 (IRF6) gene variants and the risk of isolated cleft lip or palate. N Engl J Med 2004;351 (8):769-80.
22. Zhang Z, Song Y, Zhao X, Zhang X, Fermin C, Chen $Y$. Rescue of cleft palate in Msx1-deficient mice by transgenic Bmp4 reveals a network of BMP and Shh signaling in the regulation of mammalian palatogenesis. Development 2002;129(17):4135-46.

23. Kim MH, Kim HJ, Choi JY, Nahm DS. Transforming growth factor-beta3 gene SfaN1 polymorphism in Korean nonsyndromic cleft lip and palate patients. J Biochem Mol Biol 2003;36(6):533-7.

24. Suazo J, Santos JL, Scapoli L, Jara L, Blanco R. Association Between TGFB3 and Nonsyndromic Cleft Lip With or Without Cleft Palate in a Chilean Population. Cleft Palate Craniofac J 2010;47(5): 513-7.

25. Meng L, Bian Z, Torensma R, Von den Hoff JW. Biological mechanisms in palatogenesis and cleft palate. J Dent Res 2009;88(1):22-33. DOI: 10.1177/ 0022034508327868.

26. Wu-Chou YH, Lo LJ, Chen KT, Chang CS, Chen YR. A combined targeted mutation analysis of IRF6 gene would be useful in the first screening of oral facial clefts. BMC Med Genet 2013;14:37. DOI: 10.1186/ 1471-2350-14-37.

27. Scapoli L, Palmieri A, Martinelli M, Pezzetti F, Carinci P, Tognon M, Carinci F. Strong evidence of linkage disequilibrium between polymorphisms at the IRF6 locus and nonsyndromic cleft lip with or without cleft palate, in an Italian population. Am J Hum Genet 2005; 76(1):180-3. Epub 2004 Nov 19.

28. Marazita ML, Mooney MP. Current concepts in the embryology and genetics of cleft lip and cleft palate. Clin Plast Surg 2004; 31(2):125-40.

29. Hwang SJ, Beaty TH, Panny SR, Street NA, Joseph JM, Gordon S, et al. Association study of transforming growth factor alpha (TGF alpha) TaqI polymorphism and oral clefts: indication of gene-environment interaction in a population-based sample of infants with birth defects. Am J Epidemiol 1995; 141(7): 62936.

30. Shaw GM, Wasserman CR, Lammer EJ, O'Malley CD, Murray JC, Basart AM, et al. Orofacial clefts, parental cigarette smoking, and transforming growth factor alpha gene variants. Am J Hum Genet 1996;58(3): 551-61.

31. van der Put NM, Gabreëls F, Stevens EM, Smeitink JA, Trijbels FJ, Eskes TK, et al. A second common mutation in the methylenetetrahydrofolatereductase gene: an additional risk factor for neural-tube defects? Am J Hum Genet 1998;62(5):1044-51. 
Tirado Amador LR, Madera Anaya MV, González Martínez FD. Interacciones genéticas y epigenéticas relacionadas con fisuras de labio y paladar no sindrómicas

32. Mitchell LE, Murray JC, O'Brien S, Christensen K. Retinoic acid receptor alpha gene variants, multivitamin use, and liver intake as risk factors for oral clefts: a population-based case-control study in Denmark, 1991-1994. Am J Epidemiol 2003;158(1): 69-76.

33. Crawford DC, Nickerson DA. Definition and clinical importance of haplotypes. Annu Rev Med 2005;56: 303-20.

34. Jirtle RL, Skinner MK. Environmental epigenomics and disease susceptibility. Nat Rev Genet 2007;8:253262. DOI:10.1038/nrg2045.

35. Bird A. DNA methylation patterns and epigenetic memory. Genes Dev 2002;16(1):6-21.

36. Kuriyama M, Udagawa A, Yoshimoto S, Ichinose M, Sato K, Yamazaki K, et al. DNA methylation changes during cleft palate formation induced by retinoic acid in mice. Cleft Palate Craniofac J 2008; 45(5):545-51. DOI: 10.1597/07-134.1. Epub 2008 Apr 11.

37. Grosen D, Bille C, Petersen I, Skytthe A, HjelmborgJv, Pedersen JK, et al. Risk of oral clefts in twins. Epidemiology 2011;22(3):313-9. DOI: 10.1097/EDE. Ob013e3182125f9c.

38. Murray JC. Gene/environment causes of cleft lip and/ or palate. Clin Genet 2002;61(4):248-56.

39. Pacheco SS, Braga C, Souza AI, Figueiroa JN. Effects of folic acid fortification on the prevalence of neural tube defects. Rev Saude Publica 2009;43(4):565-71. Epub 2009 May 29.

40. Jones PA. Functions of DNA methylation: islands, start sites, gene bodies and beyond. Nat Rev Genet 2012; 13(7):484-92. DOI: 10.1038/nrg3230.

41. Shi Y, Zhao X, Hsieh J, Wichterle H, Impey S, Banerjee $\mathrm{S}$, et al. MicroRNA regulation of neural stem cells and neurogenesis.J Neurosci 2010;30 (45):14931-6. DOI: 10.1523/JNEUROSCI.4280-10.2010.

42. Laurent L, Wong E, Li G, Huynh T, Tsirigos A, Ong $\mathrm{CT}$, et al. Dynamic changes in the human methylome during differentiation. Genome Res 2010;20(3):32031.

43. Zeng J, Konopka G, Hunt BG, Preuss TM, Geschwind D, Yi SV. Divergent whole-genome methylation maps of human and chimpanzee brains reveal epigenetic basis of human regulatory evolution. Am J Hum Genet 2012;91(3):455-65. DOI: 10.1016/j.ajhg.2012.07.024. Epub 2012 Aug 23.

44. Jjingo D, Conley AB, Yi SV, Lunyak VV, Jordan IK. On the presence and role of human gene-body DNA methylation. Oncotarget 2012;3(4):462-74.
45. Dunlevy LP, Burren KA, Mills K, Chitty LS, Copp AJ, Greene ND. Integrity of the methylation cycle is essential for mammalian neural tube closure. Birth Defects Res A Clin Mol Teratol 2006;76(7):544-52.

46. Ramsahoye BH, Biniszkiewicz D, Lyko F, Clark V, Bird AP, Jaenisch R. None-CpG methylation is prevalent in embryonic stem cells and maybe mediated by DNA methyltransferase 3a. Proc Natl Acad Sci U S A. 2000; 97(10):5237-42.

47. Tate PH, Bird AP. Effects of DN methylation on DNAbinding proteins and gene expression. Curr Opin Genet Dev. 1993;3(2):226-31. DOI:10.1016/0959437X(93)90027-M

48. Vila MD. Propuesta de teorías integradoras para la cefalogénesis y sus malformaciones. Rev Cubana Estomatol [revista en la Internet]. 2013 Mar [citado 2015 Mayo 25];50(1):70-93. Disponible en: http:// scielo.sld.cu/scielo.php?script $=$ sci_arttextEpid $=$ S0034-75072013000100006Elng=es.

49. Chavarriaga J, González M, Rocha A, Posada A, Agudelo A. Factores relacionados con la prevalencia de Labio y Paladar Hendido en la población atendida en el Hospital Infantil "Los Ángeles". Municipio de Pasto (Colombia), 2003-2008. Revista CES Odontología 2011;24(2):33-41.

50. Mason JB, Choi SW. Effects of alcohol on folate metabolism: implications for carcinogenesis. Alcohol 2005;35(3):235-41.

51. Haycock PC, Ramsay M. Exposure of Mouse Embryos to Ethanol During Preimplantation Development: Effect on DNA Methylation in the H19 Imprinting Control Region. Biol Reprod 2009;81(4):618-27. DOI: 10.1095/biolreprod.108.074682. Epub 2009 Mar 11.

52. Liu Y, Balaraman Y, Wang G, Nephew KP, Zhou FC. Alcohol exposure alters DNA methylation profiles in mouse embryos at early neurulation. Epigenetics 2009;4(7):500-11.

53. Bielawski DM, Zaher FM, Svinarich DM, Abel EL. Paternal alcohol exposure affects sperm cytosine methyltransferase messenger RNA levels. Alcohol Clin Exp Res 2002;26(3):347-51.

54. Ouko LA, Shantikumar K, Knezovich J, Haycock P, Schnugh DJ, Ramsay M. Effect of alcohol consumption on CpG methylation in the differentially methylated regions of $\mathrm{H} 19$ and IG-DMR in male gametes: implications for fetal alcohol spectrum disorders. Alcohol Clin Exp Res 2009;33(9):1615-27. DOI: 10.1111/j.1530-0277.2009.00993.x. Epub 2009 Jun 10. 
55. Honein MA, Rasmussen SA, Reefhuis J, Romitti PA, Lammer EJ, Sun L, et al. Maternal smoking and environmental tobacco smoke exposure and the risk of orofacial clefts. Epidemiology 2007;18(2):226-33.

56. Shi M, Christensen K, Weinberg CR, Romitti P, Bathum L, Lozada A, et al. Orofacial cleft risk is increased with maternal smoking and specific detoxificationgene variants. Am J Hum Genet 2007;80(1):76-90. Epub 2006 Dec 7.

57. Little J, Gilmour M, Mossey PA, Fitzpatrick D, Cardy A, Clayton-Smith $\mathrm{J}$ et al. Folate and clefts of the lip and palate-a U.K.-based case-control study: Part II: Biochemical and genetic analysis. Cleft Palate Craniofac J 2008;45(4):428-38. DOI: 10.1597/06151.1. Epub 2007 Dec 23.

58. Bliek JB, de Klein A, Luider TM, et al. New approaches for the identification of folate-related pathways in human embryogenesis. Cell Mol Biol (Noisy-le-Grand) 2004;50(8):939-44.

59. Sharp L, Little J. Polymorphisms in genes involved in folate metabolism and colorectal neoplasia: a HuGE review. Am J Epidemiol 2004;159(5):423-43.

60. Verkleij-Hagoort A, Bliek J, Sayed-Tabatabaei F, Ursem $\mathrm{N}$, Steegers E, Steegers-Theunissen R. Hyperhomocysteinemia and MTHFR polymorphisms in association with orofacial clefts and congenital heart defects: a meta-analysis. Am J Med Genet A 2007;143 (9):952-60.
61. Martin YN, Salavaggione OE, Eckloff BW, Wieben ED, Schaid DJ, Weinshilboum RM. Human methylenetetrahydrofolate reductase pharmacogenomics: gene resequencing and functional genomics. Pharmacogenet Genomics 2006;16(4):265-77.

62. Hernández-Díaz S, Werler MM, Walker AM, Mitchell AA. Folic acid antagonists during pregnancy and the risk of birth defects. N Engl J Med 2000;343(22): 1608-14.

63. Van Rooij IA, Ocké MC, Straatman H, Zielhuis GA, Merkus HM, Steegers-Theunissen RP. Periconceptional folate intake by supplement and food reduces the risk of nonsyndromic cleft lip with or without cleft palate. Prev Med 2004;39(4):689-94.

\section{CORRESPONDENCIA}

Meisser Vidal Madera Anaya

Departamento de investigaciones

Facultad de Odontología

Universidad de Cartagena

Campus Ciencias de la Salud

Barrio Zaragocilla

Colombia

Correo electrónico: meissermadera@gmail.com 